\title{
(RE)SIGNIFICAÇÕES DA IDENTIDADE LITERÁRIA AFRO BRASILEIRA NA PROSA DE CONCEIÇÃO EVARISTO
}

\author{
Bárbara Inês Ribeiro Simões Daibert* \\ Luciana de Oliveira Rodrigues**
}

Resumo: O presente trabalho tem como objetivo refletir sobre a prosa de Conceição Evaristo, investigando a representação das diferenças, principalmente sociais e de gênero, na escrita de seus contos, por meio da busca e da valorização da ancestralidade africana.

Palavras-chave: Identidade Africana. Ancestralidade. Literatura. Nação.

\section{Introdução}

O livro de Homi Bhabha, O local da cultura (1996), que a partir das últimas décadas do século XX estabeleceu novas formas de olhar a obra de autores periféricos e diaspóricos em sua produção literária em deslocamento, apresenta, no capítulo já amplamente citado e conhecido pela crítica, DissemiNação, em reflexões sobre a tese de Benedict Anderson, a nação como comunidade imaginada. A partir da leitura de Bhabha, forças pedagógicas e performativas atuariam de formas contrárias no interior da narrativa daquilo que seria uma "identidade nacional", negociando, através de memórias, mitos e normativas, uma forma de pensar e estar no mundo e dentro de certas fronteiras.

De fato, Bhabha apresenta a nação como construção discursiva, necessitada de vontade de nacionalidade que a justifique e mantenha. Desta forma, a identidade nacional se constrói a partir da superação de toda diferença capaz de perturbar a homogeneidade. Entretanto, segundo o autor, a atitude que ele denomina "performática" traz uma desestabilização da unidade homogênea no contexto do pensamento teórico da pós modernidade. Percebe-se a existência da heterogeneidade dentro da nação, minorias silenciadas em favor do discurso da homogeneidade nacional. Utilizando a lógica do suplemento, baseando-se no pensamento teórico de Jacques Derrida, Bhabha afirma que essas minorias mantêm em aberto uma soma que não fecha. Nesse espaço suplementar, pode ocorrer a renegociação dos espaços sociais, incluindo neles a heterogeneidade e a diferença.

Seguindo o pensamento de Bhabha, levanto a questão de que, na literatura afrobrasileira, essa renegociação pode ser suscitada através de memórias de minorias silenciadas. Nesse caso, o passado teria fundamental importância, já que sua recuperação seria capaz de reconstruir novos sentidos. Tomando como base o pensamento de Edward

\footnotetext{
* Professora adjunta no Departamento de Letras Estrangeiras Modernas da Faculdade de Letras da Universidade Federal de Juiz de Fora (UFJF). Diretora de Relações Internacionais da UFJF. Doutora em Literatura Comparada pela Universidade Federal Fluminense (UFF) e Mestre em Letras: Teoria da Literatura pela UFJF. Graduação em Letras - Língua Inglesa e suas Literaturas - Língua Portuguesa e suas Literaturas - Língua Latina e suas Literaturas pela UFJF.

E-mail: barbarasimoes2005@uol.com.br

** Doutoranda em Letras: Estudos Literários pela UFJF, Mestre em Letras pelo Centro de Ensino Superior de Juiz de Fora (CES-JF). Graduada em Letras pelo CES-JF, graduada em Educação Especial pela Universidade Metropolitana de Santos (UNIMES), Especialista em Educação Especial e Inclusiva com Ênfase em Deficiência Intelectual e Múltiplas pelo Instituto Superior de Educação Ibituruna (ISEIB). Graduada em Pedagogia pelo Centro Universitário FACVEST. Bacharel em Ciências Contábeis pela Faculdade de Ciências Contábeis e Administrativas Machado Sobrinho, Juiz de Fora. Especialização em Marketing pela Universidade Estácio de Sá. Professora de Língua Portuguesa e Professora de Apoio Educacional Especializado na Rede Estadual de Minas Gerais.

E-mail: luliorjf@gmail.com
}

IPOTESI, JUIZ DE FORA, v. 23, n. 2, p. 79-87, jul./dez. 2019 
Said, em Cultura e imperialismo,

\begin{abstract}
A invocação do passado constitui uma das estratégias mais comunsnas interpretações do presente. $\mathrm{O}$ que inspira tais apelos não é apenas a divergência quanto ao que ocorreu no passado e o que teria sido esse passado, mas também a incerteza se o passado é de fato passado, morto e enterrado, ou se persiste, mesmo que talvez sob outras formas. (SAID, 1995, p. 20)
\end{abstract}

Investigando a persistência do passado, também Leela Ghandhi (1998) aponta, em estudos sobre o pós-colonialismo, para uma resistência à amnésia do processo colonial. Segundo a autora, uma das principais funções da lembrança é trazer à tona a violência da colonização, é aproximar e tornar familiar o passado antagônico. Assim, é preciso revisitar o passado a fim de entender e interrogar o processo, já que, segundo a autora, a simples tentativa de esquecer e banir o passado colonial não é uma superação deste, mas uma repressão, que deixa para trás a presença do resíduo de algo não-resolvido. (GHANDHI, 1998, p. 4).

Incômodo, este resíduo permanece também nos países onde a escravidão deixou suas marcas. Desta forma, trazemos a hipótese, neste trabalho, de que a escrita de Conceição Evaristo, autora afro-brasileira contemporânea, estabelece, pelas pontes com a ancestralidade e em resgates de memória, uma renegociação dos sentidos e do lugar da minoria negra esquecida pela Ordem e pelo Progresso que marcaram a narrativa pedagógica do Brasil.

\title{
A ancestralidade na obra de Conceição Evaristo
}

Refletindo sobre a descontinuidade, o desmembramento e a descentralização da literatura pós-moderna (termo este utilizado para teorizar as novas tendências poéticas), e, ainda, sobre a renegociação da identidade nacional a partir de narrativas de minorias historicamente excluídas do processo de formação do Brasil, destaca-se a literatura afrobrasileira. Em sua diferença, é possível entrever um novo olhar a tudo que antes fora dito para e sobre o negro; este que antes era objeto de uma escritura torna-se sujeito da mesma, renegociando uma nova fluida identidade, sobretudo, literária. Nesse contexto, insere-se a prosa de Conceição Evaristo.

A autora, herdeira de forte herança cultural afro, apresenta em seus textos a busca e a valorização da ancestralidade africana, voltando-se para a construção de uma nova imagem do povo negro que questiona os estereótipos estabelecidos. Evaristo nos remete ao que Ponce (2014) aponta como uma voz autoral afrodescendente, explícita ou não no discurso, vista, sobretudo, "como um ponto de vista ou lugar de enunciação política e culturalmente identificado à afrodescendência, como fim e começo". (PONCE, 2014, p. 165).

Esse conceito aparece no conto Olhos d'água de Evaristo com a presença da voz autoral, da temática e do ponto de vista, que apontam as relações identitárias e enfatizam a necessidade de se reatar a conexão com a ancestralidade, a hereditariedade e a busca pela identidade, recorrendo-se à imagem dos olhos. No referido conto, a narradora-personagem reflete acerca da dúvida quanto à cor dos olhos de sua mãe, seguida por lembranças da infância que engendram reflexões e a direcionam para um retorno à cidade natal, no intuito de encarar a figura materna e projetar seu olhar no dela para desvendar sua cor. A narradorapersonagem relembra as experiências que marcaram sua infância e, neste jogo de recordações, acaba por (con)fundir suas próprias memórias com as lembranças de sua mãe, como um elo estabelecido entre passado e futuro que se concretizará no desfecho do conto, quando, em frente à filha, a narradora brinca de buscar a verdadeira cor de seus olhos:

IPOTESI, JUIZ DE FORA, v. 23, n. 2, p. 79-87, jul./dez. 2019 
Hoje, quando já alcancei a cor dos olhos de minha mãe, tento descobrir a cor dos olhos de minha filha. Faço a brincadeira em que os olhos de uma são o espelho dos olhos da outra. E um dia desses me surpreendi com um gesto de minha menina. Quando nós duas estávamos nesse doce jogo, ela tocou suavemente o meu rosto, me contemplando intensamente. E, enquanto jogava o olhar dela no meu, perguntou baixinho, mas tão baixinho como se fosse uma pergunta que para ela mesma, ou como estivesse buscando ou encontrando a revelação de um mistério ou de um grande segredo. Eu escutei quando, sussurrando, minha filha falou:_Mãe, qual é a cor tão úmida de seus olhos? (EVARISTO, 2011, p. 174-175).

Esse fragmento exemplifica vestígios da relação de respeito e devoção dos povos africanos com os seus ancestrais. De acordo com Silva (2018), muitas culturas africanas têm os idosos como os sábios da comunidade, ou seja, consideram os idosos como aqueles que detêm o conhecimento e podem garantir a continuidade do grupo. Assim, as tradições, os costumes, os valores e muitas das marcas identitárias das comunidades africanas são estabelecidas de acordo com a relação que o grupo possui com os seus antepassados. Em Olhos d'água,a ancestralidade ligada à voz autoral também se manifesta no ato de se recordar das mulheres de sua família e de seus ancestrais desde a África:

\begin{abstract}
Havia anos que eu estava fora de minha cidade natal. Saíra de minha casa em busca de melhor condição de vida para mim e para minha família: ela e minhas irmãs tinham ficado para trás. Mas eu nunca esquecera a minha mãe. Reconhecia a importância dela na minha vida, não só dela, mas de minhas tias e todas as mulheres de minha família. E também, já naquela época, eu entoava cantos de louvor a todas as nossas ancestrais, que desde a África vinham arando a terra da vida com suas próprias mãos, palavras e sangue. Não, eu não esqueço essas senhoras, nossas Yabás, donas de tantas sabedorias (EVARISTO, 2010, p. 173-174).
\end{abstract}

Para a narradora, reconhecer essas mulheres e a importância de sua formação leva ao auto reconhecimento e também à descoberta de si mesma, visto que mais do que expressar homenagem a essas mulheres, as recordações revelam uma busca por traços de uma identidade perdida. Diretamente ligada à voz autoral, a temática presente nesse conto dialoga com uma possível identidade negra e com a ancestralidade, utilizando-se da imagem dos olhos para simbolizar a união estabelecida entre passado, presente e futuro, que vai da avó até a neta.

Nesse processo de (re)significações identitárias, Pollak (1992) enfatiza a importância da memória como um elemento constituinte do sentimento de identidade, tanto individual como coletiva, na medida em que ela é também um fator extremamente importante do sentimento de continuidade e de coerência de uma pessoa ou de um grupo em sua reconstrução de si. A construção da identidade é um fenômeno que se produz em referência aos outros, em referência aos critérios de aceitabilidade, de admissibilidade, de credibilidade, e que se faz por meio da negociação direta com outros. A memória e identidade podem perfeitamente ser negociadas, e não são fenômenos que devam ser compreendidos como essências de uma pessoa ou de um grupo. "Se é possível o confronto entre a memória individual e a memória dos outros, isso mostra que a memória e a identidade são valores disputados em conflitos sociais e intergrupais, e particularmente em conflitos que opõem grupos políticos diversos". (POLLAK, 1992, p.205).

Ao olhar para a diversidade e não para a homogeneidade da experiência negra e reconhecer outros tipos de diferenças que localizam, situam e posicionam os povos diaspóricos, percebemos que nossas diferenças étnico-raciais não nos constituem inteiramente. Estamos sempre negociando diferentes tipos de diferenças, de gênero, sexualidade, classe. O deslocamento da diversidade cultural para a diferença cultural produz

IPOTESI, JUIZ DE FORA, v. 23, n. 2, p. 79-87, jul./dez. 2019 
uma cisão no modo de entender a nossa contemporaneidade, introduzindo, assim, a criação de um espaço cultural híbrido.

Assim, falar de sujeito, para Bhabha (1996), significa falar da constituição de sujeitos culturais híbridos, bem como falar de cultura significa pensar para além da oposição sujeito/cultura. O local da cultura/locais da cultura convoca, para o autor, o marginal e o estranho, o entre-lugar deslizante, a desestabilização dos essencialismos; convoca, enfim, o espaço-cisão da enunciação, um elo como espaço indeterminado dos sujeitos da enunciação. A escrita desse texto é uma escrita situada nas margens deslizantes do deslocamento cultural e profundamente comprometida com uma perspectiva teórica que toma como ponto paradigmático de partida o hibridismo cultural e histórico do mundo pós-colonial, inevitável sobretudo no interior dos países que vivem com as consequências da diáspora forçada dos africanos.

Nesse espaço de negociações, o campo das identidades se insere no espaço em que o poder, de acordo com Foucault (1979) é uma relação de forças que se encontra presente, e em constante movimento, em todos os espaços sociais, sejam eles públicos ou privados, gerando tensões que se expressam em toda relação. A resistência comparece, então, como parte constitutiva dessa relação, pois ela está sempre presente, e se configura como o grito do descontentamento anunciando o exercício da liberdade. Partindo da afirmação inicial de Hall (2006) sobre hegemonia cultural, ou seja, a alteração das disposições e configurações do poder cultural, entende-se que as identidades e as diferenças não são naturais, nem essenciais, são produzidas social e culturalmente, atravessadas pelas relações de poder, isto é, as identidades e as diferenças são negociadas.

Quando falamos em (re)significações da escrita literária afro-brasileira, destacamos a importância da fala neste espaço de negociações. A crítica e teórica indiana Spivak em seu ensaio: Pode o subalterno falar? (2010) demonstra a sua preocupação com o processo através do qual os estudos pós-coloniais ironicamente reinscrevem, cooptam, e ensaiam os imperativos da dominação política neocolonial, a exploração econômica e o apagamento cultural do colonizado. Conceição Evaristo, por meio da escrita literária, cria condições que possibilitam ao oprimido se articular e, como consequência, permite também que ele seja ouvido. Embora sua escrita contenha marcas de formas de dominação que incluem separações, deslocamentos e desmembramentos, a autora utiliza-se de sua "escrevivência", e reconstrói e renegocia a identidade de mulher negra e pobre. Com isso, a escritora elabora estratégias de reversão da condição fragilizada da mulher negra e modos alternativos de redefinição de suas identidades, ao aproximar-se por um lado e distanciar-se por outro da realidade transformada em ficção com o objetivo de trazer um diferente olhar para a cena literária habitual, em que os estereótipos e os lugares dos negros, brancos, pobres e ricos estão muito demarcados.

\section{Estratégias de subversão da ordem ocidental na escrita de Conceição Evaristo}

Na coletânea Insubmissas lágrimas de mulheres (2011), a autora narra treze contos em forma de relatos de vida de diferentes mulheres negras, pelos quais enuncia os mais variados discursos sobre as inquietações, os medos, os sonhos, as orientações sexuais, os desafios e as relações afetivas dessas narradoras que se negam a ceder às pressões devastadoras das suas cruéis experiências pessoais com o racismo, o preconceito, o sexismo e as degradantes convenções étnico-raciais que retratam as suas experiências de trajetórias de vida. Suas personagens são mulheres insubmissas que têm o poder do discurso e capacidade de se autonomear. Destacamos a primeira personagem do livro Natalina Soledad, que, embora tenha nascido mulher, a sétima, depois de seis filhos homens, foi vista como sendo a decepção do pai, que por ter gerado uma menina se considerava então menos homem. Deu-lhe o nome

IPOTESI, JUIZ DE FORA, v. 23, n. 2, p. 79-87, jul./dez. 2019 
de Troçoleia Malvina Silveira. Depois de crescida, a menina intenta apenas o grande e único propósito de mudar de nome:

\footnotetext{
Inventar para si outro nome. E, para criar outro nome, para se rebatizar, antes era preciso esgotar, acabar, triturar, esfarinhar aquele que haviam lhe imposto. Pacientemente, a menina Silveirinha esperou. A moça Silveirinha esperou. A mulher Silveirinha esperou. E nas diversas andanças do tempo sobre o corpo dela, muitos acontecimentos (EVARISTO, 2011, p. 23).
}

De fato, a coletânea de Evaristo nos apresenta diversos contos onde as personagens assumem o controle da sua própria sexualidade: Rosário Imaculado, que evita engravidar e interrompe as gestações; Isaltina Campo Belo, que resolve assumir sem culpas a sua homossexualidade; Saura Amarantino, que rejeita a filha por ter sido fruto de uma gravidez indesejada; Regina Anastácia, que desmistifica a crença de que a mulher negra só serve para dar prazer, quando consegue casar com um fidalgo branco e dele obter carinho e respeito. Evaristo esboça em sua escrita a teoria de Ferreira (2009), de que somos feitos de performances discursivas e podemos engendrar outros discursos para outras ações, em que podemos inaugurar novos sentidos para a nossa vida e, portanto, reinventar nossas histórias (FERREIRA apud LIEBIG, 2009).

Assim, no desfecho do relato sobre a vida de Ponciá, a voz narrativa vai apresentá-la andando em círculos e desfiando "fios retorcidos de uma longa história" (EVARISTO, 2003, p.131) enquanto molda, com as próprias mãos, a matéria viva da própria vida. De volta às águas do rio de sua infância, juntamente com a mãe e o irmão Luandi, Ponciá Vicêncio se constrói como "elo e herança de uma memória reencontrada pelos seus". (EVARISTO, 2003, p.132). Quando a personagem vai para as águas do rio, a voz narrativa rompe com a teia de desencontros que marca sua vida, incorpora em seu corpo a marca do vazio e a conduz para um espaço onde ela não se perderá jamais, onde no fluir das águas, poderá emendar o tempo lembrado e esquecido da personagem, agarrando o seu passado-presente-e-o-que-há-de-vir num ato de fazer, de reinventar sempre e sempre, que lhe permita significar discursivamente as mutilações e ausências que também conformam o corpo feminino negro de Ponciá Vicêncio. (MOREIRA, 2016,p.115).

Sobre as estratégias capazes de fazer diferença e de deslocar as disposições de poder, destacamos a cultura popular negra, que tem permitido trazer à tona elementos de um discurso que é diferente, outras formas de vida, outras tradições de representação.Cortes (2016) aponta que a transgressão aqui está na criação de uma outra narrativa que se apóia na tradição dos seus, na ancestralidade e por isso é reversa. Dupla. Para ela, é o impossível devir literário que mobiliza nessa escrita, e num gesto de sabotagem da língua instituída, na gagueira, surge o silêncio que rasura o discurso do opressor e aponta para a força da língua menor, da particularidade dos povos e na vontade política que dialoga com as estratégias discursivas da linguagem literária.

Para Jameson, a descrição teve um papel importante no discurso colonial, classificando e dominando ideologicamente o sujeito colonial, preparando um terreno a partir do qual julgamentos de classificação, generalização e valor pudessem ser feitos. Com isso, o autor cria uma imagem de literatura do terceiro mundo como sendo, ao mesmo tempo, derivada, inferior esteticamente e atrasada em relação à do primeiro mundo. Sobretudo, afirma que o romance de terceiro mundo parece já-lido ao leitor de primeiro mundo, e presume que a percepção precisa da novidade, do produto mais recente. Evaristo utiliza a memória como elo de ligação entre o passado e presente, no intuito de estabelecer as relações identitárias, atestando ser necessário que o leitor vá além daquilo pertencente a um procedimento literário anterior, a fim de entrar em contato com o novo, com uma obra que provoque o estranhamento em relação a procedimentos cristalizados.

IPOTESI, JUIZ DE FORA, v. 23, n. 2, p. 79-87, jul./dez. 2019 
A estratégia de inclusão do imprevisível nas novas narrativas de Conceição Evaristo, destaca-se na obra Histórias de leves enganos e parecenças (2016), na qual a incursão da imprevisibilidade, isto é, do estranho, nos contos e na novela parece mais se aproximar do que se concebe como realismo animista (termo cunhado pelo escritor angolano Pepetela), perspectivado em diversas narrativas africanas. Isto porque a existência da atuação de forças da natureza, da alteração dos fenômenos que modificam a ordem natural das coisas, a crença em entidades capazes de intervir na rotina dos personagens, etc. são artifícios concebidos por um modus operandi revelador da maneira de pensar, de ser e de existir de uma dada comunidade cujas origens advêm da diáspora africana.

De acordo com o prefácio de Histórias de leves enganos e parecenças, Silva (2016) ressalta as estratégias apontadas nos contos e na novela em discussão que redimensionam o fazer literário de teor inclusivo quanto ao que não está na "ordem natural das coisas" que conduz a um pensamento animista, caracterizado não meramente por uma "representação", mas como forma de "apreensão do mundo" (SOYINKA APUD SILVA, 2016a). Esse modo de apreensão dos mitos, rituais e valores ancestrais tendem a recusar uma nova colonização e validar um modo de ser e existir revigorado no ato da "escrevivência" evaristiana.

$\mathrm{O}$ animismo está relacionado a movimento e com a ideia de harmonia com a natureza, com as forças vivas da natureza e, ainda, um pertencimento de mundo, a partir de seu toque efetivo e comovente. Ora, o toque de mundo é o que o anima, é a anima, a sua alma que é representada pelas forças da natureza. Para Garuba (2012), por meio de uma concepção animista de realidade e de mundo, as estórias africanas buscam ressignificar os modos de vida dos antepassados e ampliar as possibilidades de significação da relação entre a tradição e a modernidade. Para ele, esse tipo de escrita subverte as convenções do realismo, e a substituição pelo termo realismo animista parece ser a mais apropriada de classificar essa narrativa, onde os elementos da cultura tradicional coexistem c com os elementos modernos

Sobre as estratégias capazes de deslocar ou incomodar as disposições de poder, destacamos a cultura popular negra, que tem permitido trazer à tona elementos de um discurso que é diferente, outras formas de vida, outras tradições de representação. Cortes (2016) aponta que a transgressão nesse caso está na criação de uma outra narrativa que se apoia na tradição dos seus, na ancestralidade e por isso é reversa e dupla. Assim, o impossível devir literário é o que mobiliza essa escrita, num gesto de sabotagem da língua instituída: na gagueira, surge o silêncio que rasura o discurso do opressor e aponta para a força da língua menor, da particularidade dos povos e na vontade política que dialoga com as estratégias discursivas da linguagem literária.

O inconsciente animista (GARUBA, 2012, p. 242), que impulsiona a consciência de si e do grupo, patenteia as ações dos sujeitos que transitam nos contos e na novela de Conceição Evaristo, além de ser uma estratégia discursiva que parece remeter-nos para uma desconstrução de paradigma abrigado no pensamento binário das culturas hierarquizantes. A lógica do pensamento animista fornece uma abertura para se pensar em outras histórias da modernidade, além da trajetória linear e teleológica da narrativa histórica convencional. Ao empregar a expressão "reencantamento de mundo", Garuba (2018) chama a atenção para o reverso do processo que Max Weber descreve: o reencantamento é um processo pelo qual elementos do pensamento mágico não são deslocados, mas, pelo contrário, continuamente assimilam os novos desenvolvimentos em ciência, tecnologia e organização dentro de uma visão de mundo "mágica". Ao invés de "desencantamento", ocorre um persistente reencantamento, e o racional e científico são apropriados e transformam-se no mágico e no místico. No interior dessa transformação, a ancestralidade renegocia identidades anteriormente esquecidas pelo cânone e pela narrativa oficial da nação.

IPOTESI, JUIZ DE FORA, v. 23, n. 2, p. 79-87, jul./dez. 2019 


\title{
Considerações finais
}

A escrita de Evaristo utiliza traços de animismo e possui um caráter de denúncia com base na experiência, como possibilidade de leitura do que foi negligenciado pelas entrelinhas da literatura canônica, em que sua representação no espaço literário dialoga com o conceito de Escrevivência proposto pela autora. Conforme suas palavras:

\begin{abstract}
Essas escritoras buscam na história mal contada pelas linhas oficiais, na literatura mutiladora da cultura e dos corpos negros, assim como em outros discursos sociais, elementos para comporem as suas escritas. Debruçam-se sobre as tradições afrobrasileiras, relembram e bem relembram as histórias de dispersão que os mares contam, se postam atentas diante da miséria e da riqueza que o cotidiano oferece, assim como escrevem as suas dores e alegrias íntimas. (EVARISTO, 2005, p. 204)
\end{abstract}

Nas obras dessa autora, encontramos uma estreita relação das protagonistas com seus ancestrais, dos quais recebem influência que refletem na renegociação de uma identidade e na maneira como elas se relacionam com o mundo e consigo mesmas. Nessas relações, as identidades estão em jogo com a diferença, e daí podem surgir significados posicionais e relacionais, sempre em deslize ao longo de um espectro sem começo nem fim" (HALL, 2009, p. 33). Assim, ao reverenciar os seus antepassados, a narrativa de Evaristo estabelece um elo entre passado e presente, a vida e a morte, a continuidade e a mudança. Nessa nova relação,sabemos, os significados não podem ser fixados. Precariamente, portanto, surge uma outra fala, performativa, que entretanto renegocia espaço, heranças e identidades anteriormente negligenciadas pela narrativa nacional estabelecida.

\section{(RE)SIGNIFICATION OF AFRICAN BRAZILIAN LITERARY IDENTITY IN THE FICTION OF CONCEIÇÃO EVARISTO}

Abstract: This paper aims to reflect on the prose of Conceição Evaristo, investigating the representation of differences, mainly social and gender ones, in the writing of her tales, through the search and appreciation of African ancestry.

Key words: African Identity. Ancestry. Literature. Nation.

\section{Referências}

BARROS, José d'Assunção. A historiografia pós-moderna. Ler História, n. 61, 2011, p.147167. Disponível em: <https://journals.openedition.org/lerhistoria/1655>. Acesso em: 27 abr. 2019.

BHABHA, Homi K. O local da cultura. Belo Horizonte: UFMG, 1996.

CÔRTES, Cristiane. Diálogos sobre escrevivência e silêncio. In: DUARTE, Constância Lima; CÔRTES, Cristiane; PEREIRA, Maria do Rosário A. (orgs). Escrevivências: identidade, gênero e violência na obra de Conceição Evaristo. Belo Horizonte: Idea, 2016. p. 51-60.

EVARISTO, Conceição. Olhos d'água. Rio de Janeiro: Pallas, 2010.

IPOTESI, JUIZ DE FORA, v. 23, n. 2, p. 79-87, jul./dez. 2019 
Insubmissas lágrimas de mulheres. Belo Horizonte: Nandyala, 2011.

. Ponciá Vicêncio. Belo Horizonte: Mazza, 2003.

História de leves enganos e parecenças. Rio de Janeiro: Malê, 2016.

Gênero e etnia: uma escre(vivência) da dupla face. In: MOREIRA, Nadilza Martins de Barros; SCHNEIDER, Diane (eds.). Mulheres no mundo, etnia, marginalidade e diáspora. João Pessoa: Ideia, 2005. p. 201-212. Disponível em:

https://pt.scribd.com/document/177337990/Conceicao-Evaristo-Genero-e-etnia-uma-escrevivencia-de-dupla-face. Acesso em: 20 abr. 2019.

FOUCAULT, Michel. Microfísica do poder. Organização e tradução de Roberto Machado. Rio de Janeiro: Graal, 1979.

GANGHI, Leela. Postcolonial theory: a critical introduction. New York: Columbia University, 1998.

GARUBA, Harry. Explorações do realismo animista: notas sobre a leitura e a escrita da literatura, cultura e sociedade africana. Tradução Elisângela da Silva Tarouco. Nonada: Letras em Revista, Porto Alegre, v. 2, n. 19, p. 235-256, out. 2012. Disponível em: http://www.redalyc.org/pdf/5124/512451673021.pdf. Acesso em: 02 dez. 2018.

Reflexões provisórias sobre o animismo, modernidade/colonialismo e a ordem africana do conhecimento. Tradução Alice Botelho Peixoto. CESPUC, n. 32, p. 123-131, jan./jun. 2018. Disponível em:

http://periodicos.pucminas.br/index.php/cadernoscespuc/article/view/17021. Acesso em: 14 mar. 2019.

HALL, Stuart. Que "negro" é esse na cultura negra? In: Da diáspora: identidades e mediações culturais. Organização Liv Sovik. Tradução Adelaine La Guardia Resende et al. Belo Horizonte: UFMG; Brasília: Representação da UNESCO no Brasil, 2009.

. A identidade cultural na pós-modernidade. 11. Ed. Tradução Tomaz Tadeu da Silva e Guacira Lopes Lobo. Rio de Janeiro: DP\&A, 2006.

JAMESON, Fredric. Pós-modernismo: a lógica cultural do capitalismo tardio. 2. ed. São Paulo: Ática, 1997.

LIEBIG, Sueli Meira. "Escrevivências": Evaristo e a subversão de gênero em Insubmissas lágrimas de mulheres. XII Colóquio Nacional Representações de gênero e sexualidades. 08 a 10 de junho de 2016, Campina Grande, PB. Disponível em:

file:///C:/Users/Windows\%2010/Downloads/TRABALHO_EV053_MD1_SA6_ID571_30042 016200422.pdf. Acesso em: 16 fev. 2019.

MOREIRA, Terezinha Taborda. Silêncio, trauma e escrita literária. In: DUARTE, Constância Lima; CÔRTES, Cristiane; PEREIRA, Maria do Rosário A. (orgs). Escrevivências:

identidade, gênero e violência na obra de Conceição Evaristo. Belo Horizonte: Idea, 2016. p. 109-119.

IPOTESI, JUIZ DE FORA, v. 23, n. 2, p. 79-87, jul./dez. 2019 
POLLAK, Michael. Memória e identidade social. Estudos Históricos. Rio de Janeiro, v. 5. n. 10, p. 200-212, 1992. Disponível em:

http://www.pgedf.ufpr.br/memoria\%20e\%20identidadesocial\%20A\%20capraro\%202.pdf. Acesso em: 09 maio 2019.

PONCE, Eduardo Souza; GODOY, Maria Carolina de. Ancestralidade e identidade em "Olhos d'água" de Conceição Evaristo. Anais do VIII Colóquio de Estudos Literários. Ferreira Cláudia C.; Jacicarla S.; Brandini Laura T.(orgs). Londrina, 06 e 07 ago. 2014. p. 163-170. Disponível em:

http://www.uel.br/eventos/estudosliterarios/pages/arquivos/Eduardo\%20Ponce\%20e\%20Mari a\%20Carolina\%20Godoy_Texto\%20Completo.pdf. Acesso em: 18 abr. 2019.

SAID, Edward. Cultura e imperialismo. São Paulo: Companhia das Letras, 1995.

SILVA, Assunção de Mari Souza e. "E assim tudo se deu": as histórias de leves enganos e parecenças. In: DUARTE, Constância Lima; CÔRTES, Cristiane; PEREIRA, Maria do Rosário A. (orgs). Escrevivências: identidade, gênero e violência na obra de Conceição Evaristo. Belo Horizonte: Idea, 2016. p. 295-306.

SILVA, Franciane da Conceição. A presença da ancestralidade em narrativas de Conceição Evaristo e Mia Couto. Cadernos Cespuc, n. 32, jan./jul. 2018. Disponível em: http://periodicos.pucminas.br/index.php/cadernoscespuc/article/view/16962/13446. Acesso em: 12 abr. 2019.

SPIVAK, GayatriChakravorty. Pode o subalterno falar? Tradução Sandra Regina Goulart Almeida, Marcos Pereira Feitosa e André Pereira Feitosa. Belo Horizonte: UFMG, 2010.

Data de submissão: 16/05/2019.

Data de aceite: 29/08/2019. 